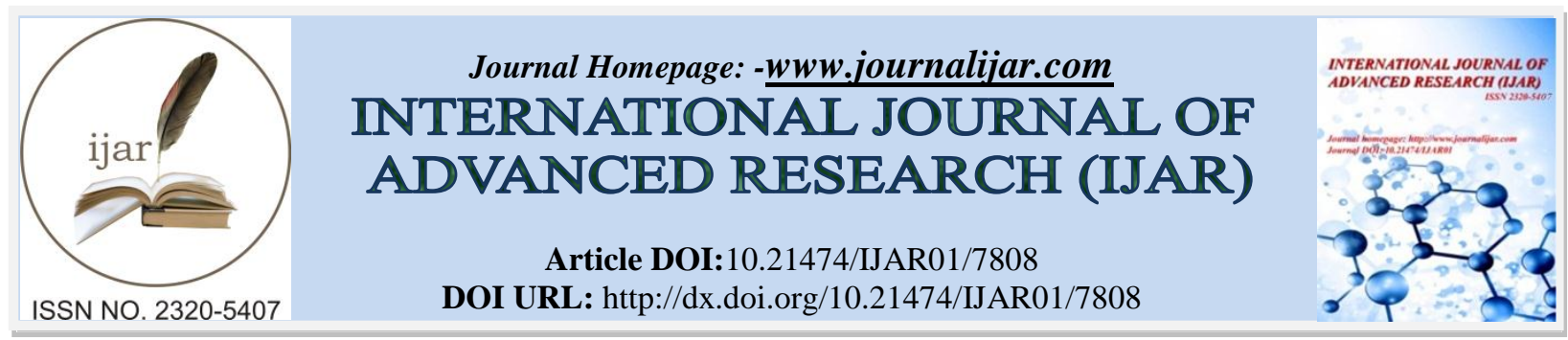

RESEARCH ARTICLE

\title{
COMPARISON OF EFFICIENCY OF OXYTOCIN DRUG WITH MISOPROSTOL IN INDUCTION PREGNANT WOMEN ABORTION IN BAGHDAD.
}

Khulood Abdul Wahab Jumaah", Abbas A. J. AL - Salihi ${ }^{2}$, and Hanaa Mohammed Moheyaldeen ${ }^{1}$.

1. Ministry of Health - Baghdad Medical office - Al-Karkh, - Karkh Maternity Hospital, Baghdad, IRAQ.

2. High Institute of Infertility Diagnosis and ART's, AL-Nahrain University, Baghdad, IRAQ.

\section{Manuscript Info}

Manuscript History

Received: 5 August 2018

Final Accepted: 7 September 2018

Published: October 2018

Keywords: -

Misoprostol, oxytocin, induction ofpregnant.

\section{Abstract}

The present study aimed to compare the effectiveness of the studyOxytocin with misoprostol in the induction of labor to abortion in a sample of pregnant women in Baghdad Hospital. The study was divided Women who Need an abortion because of fetal death inthe sample consisted of (100) women who needed to have an abortion at the end of pregnancy due to fetal death, and 20 women needing abortion at the beginning of pregnancy too, they were divided into two groups (50) women receive misoprostol, and (50) women receive a drug OxytocinComparisons were made between women. The study also consisted of 20 women with early pregnancy who were divided into two groups each receiving a drug similar to the previous oneMisoprostol was found to be more effective than women in both early and delayed pregnancies.

Copy Right, IJAR, 2018,. All rights reserved.

\section{Introduction: -}

Most women go into labor on their own. When this does not happen or when there is a medical need, other methods may be used to induce (bring on) labor. Labor induction causes a pregnant woman's uterus to contract. It also causes the cervix to soften (ripen), open (dilate), and thin out (efface). Typically, labor is not induced before 41 weeks of the pregnancy unless there is a medical reason. There are several choices for inducing labor. Your doctor or midwife will help you choose what is best for you and your baby ${ }^{(1)}$.

Most labor starts normally. Although natural delivery (without any means of agitation) is preferable, it sometimes requires a minor intervention to help a pregnant woman develop her baby. Birth is instigated when the doctor resorts to artificial stimuli to complete the procedure. Incubation is instigated when pregnancy becomes more serious than immediate delivery ${ }^{(2)}$. Induction of labor may take more than one day, especially if this is your first baby. Your doctor or midwife may start with a process called cervical ripening, since an induction may take several days. Cervical ripening helps the cervix become soft and thin. A medication taken by mouth or placed in the vagina to help the cervix ripen requires you to stay in the hospital. Another method is the placement of a small water-filled balloon, which passes through the vagina into the cervix. The balloon stays in the cervix for 12-24 hours. Some women may be able to go home with the balloon in place and return in the morning for the next step of the 
induction. For your comfort, and to help your labor, you will be encouraged to remain active ${ }^{(3)}$. Induction of labor is a process used to start labor artificially. The aim of induction of labor is to start your contractions, which leads to the softening and opening of your cervix (neck of the womb) so you can give birth to your baby. While in most pregnancies labor starts naturally between $(37,42)$ weeks, there are a number of reasons why we recommend induction of labor, the most common of which is being overdue ${ }^{(4)}$.

Oxytocin may be used to induce labor. The so-called polypeptide oxytocin is produced in the hypothalamus region and is excreted from the posterior lobe of the ovary. The external oxytocin gives periodic uterine contractions observed since the 20th gestational week and the response increases with the age of conception, to increase its receptors in the uterine muscle. Misoprostol, which is found in the form of a pill, is also rapidly absorbed, whether vaginal or oral, and reaches its concentration within an hour after oral administration ${ }^{(5)}$.

\section{The problem of research:}

Induction of labor may take more than one day, especially if this is your first baby. Your doctor or midwife may start with a process called cervical ripening, since an induction may take several days. Cervical ripening helps the cervix become soft and thin. A medication taken by mouth or placed in the vagina to help the cervix ripen requires you to stay in the hospital. Another method is the placement of a small water-filled balloon, which passes through the vagina into the cervix. The balloon stays in the cervix for 12-24 hours. Some women may be able to go home with the balloon in place and return in the morning for the next step of the induction. For her comfort, and to help her labor, she will be encouraged to remain active ${ }^{(6)}$.

There are many different situations in obstetrics where there is the need for labor induction in women with unripe services. This indication stems from a situation where the continuation of pregnancy may be life-threatening for the mother and/or fetus. Such induction is frequently prolonged, exhausting and very often unsuccessful, resulting in a cesarean section. Among the pharmacological agents used for labor induction, oxytocin and misoprostol are the most common. Several studies have shown that continuous intravenous infusion of oxytocin is less efficient, particularly when there are unfavorable cervical conditions, leading frequently to a cesarean section, because of induction failure. In such cases, another pharmacological agent, perhaps a prostaglandin, should be used to favor cervical ripening, at least initially.

The researcher began in her current study to address the effectiveness of using only two drugs without the other methods, because it is most common in the study area, where it will address the effectiveness of oxytocin with misoprostol in the induction of labor for abortion in pregnant women in Baghdad Hospital.

Oxytocin is the only drug currently approved by the Food and Drug Administration for the induction of labor. It is well established that the outcome of laborinduction depends on the characteristics of the cervix, with the cesarean rate approaching $60 \%$ when the Bishop score is less than $4^{(7)}$.

Recently, there has been considerable interest in the use of misoprostol, a prostaglandin El analog, for both cervical ripening and labor induction ${ }^{(8)}$. With misoprostol, as with oxytocin, the initial dose, the dosing interval, and maximum allowable dose vary considerably, the optimal regimen that will initiate and maintain effective labor, without adversely affecting the fetus, has not been established ${ }^{(9)}$. The purpose of the current study is to compare the safety and efficacy of misoprostol with that of intravenous oxytocin for induction of labor, regardless of cervical status. We hypothesized that induction of labor with misoprostol would result in a shorter mean induction-todelivery interval compared with oxytocin, and that despite the association of misoprostol with uterine tachysystole, its use would not be associated with adverse fetal outcome. 


\section{Importance of studying:}

The importance of the study stems from the importance of the process of induction of labor in itself, it is a critical stage that needs great attention. The importance of the study is also shown by its focus on two drugs that are widely used and should therefore be studied and studied to identify the most effective in the induction of labor.

\section{Objectives of the study:}

The current study seeks to detect the effectiveness of oxytocin with misoprostol in the induction of labor for abortion in 50 pregnant women in Baghdad Hospital, whose fetus died due to delayed birth.

\section{Theoretical background and previous studies:}

Several studies have been performed, especially in developed countries, using of oxytocin drug with misoprostol for cervical ripening and labor induction, particularly in cases where the Bishop Index6 is lower than seven, in which its effectiveness was shown. However, the widespread use of this drug is limited because of its high cost and thermal instability, which leads to difficult storage, plus the occasional need to use oxytocin after cervical ripening ${ }^{(10)}$. In Brazil, this drug is not at present being marketed. Misoprostol (Cytotec), a synthetic E1 methyl analog prostaglandin, is at present receiving more attention as a cervical modifying agent and labor inductor, as it has the advantages of low cost, stability in relation to temperature, easy handling and storage, and also easy administration (vaginal or endocervical) ${ }^{(11)}$. However, there is still a need to better establish its safety so as to avoid hyperstimulation syndrome, which could result in undesirable consequences for the newborn. During the last few years, many studies have been carried out on live fetus pregnancies, to establish the best dose, administration route and interval between doses for this cervical ripening and labor induction drug and compare it to oxytocin and dinoprostone $^{(12)}$. A meta-analysis performed in 1998 concluded that vaginal misoprostol seems to be more effective for cervical ripening and labor induction than the conventional methods. However, it emphasized the need for complementary studies in order to achieve safer results in relation to hyperstimulation syndrome and perinatal results ${ }^{(13)}$. According to the published studies, the vaginal dose of misoprostol that has shown the greatest safety and efficiency for the mother and newborn is $25 \mu \mathrm{g}$ at 4-6 hourly intervals ${ }^{(14)}$. In fact, a recent study on the pharmacokinetics of this drug showed that its serum levels, after vaginal administration, remain stable for at least 4 hours, suggesting that the ideal time interval between doses should be greater than 4 hours $18^{(15)}$.

The incidence of cesarean deliveries is quite high. Some of them take place because of elective anticipation due to maternal and/or fetal complications that are associated with a high level of unsuccessful oxytocin induction ${ }^{(16)}$. In view of this, a randomized controlled trial was proposed, in order to study the safety and effectiveness of vaginal misoprostol given at four-hourly intervals for cervical ripening and labor induction, in comparison with oxytocin infusion, in pregnant women with unripe cervices and live fetuses ${ }^{(17)}$.

\section{Methods of labor}

There are four common ways to induce labor. Sometimes more than one method is used. The method that is right for you depends on your individual circumstances and the reason for your induction. It also depends on how 'favorable' or 'ready' your cervix is for labor. You can think of induction as happening in two parts. Part 1 aims to soften and open your cervix (make it ready for induction) and part 2 aims to start or increase your contractions ${ }^{(18)}$.

A balloon catheter (with one or two balloons) A soft thin tube (catheter) is passed into your vagina and through your cervix. Then a small balloon at the end of the catheter is filled with water. The balloon helps the cervix to soften and 
open up (dilate). The balloon catheter is usually left in for about 12 hours. Sometimes the catheter will fall out by itself as your cervix opens ${ }^{(19)}$.

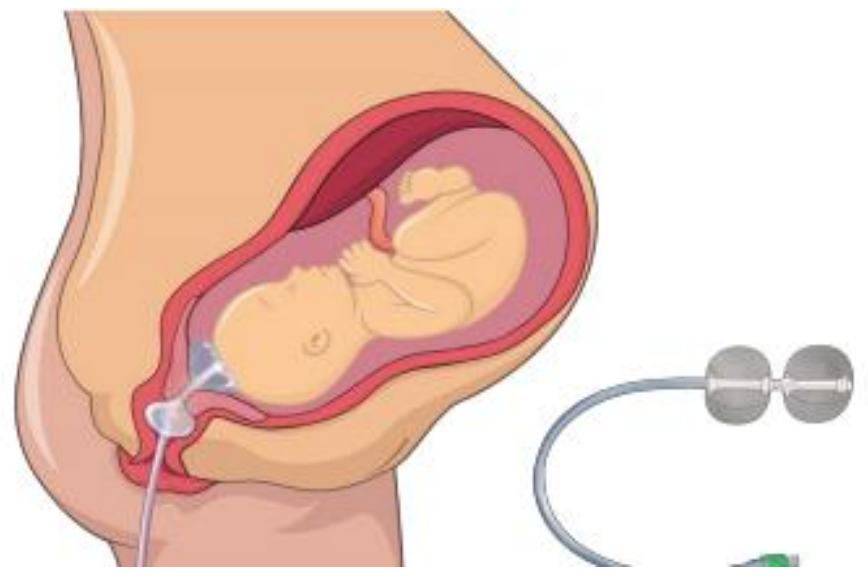

\section{Prostaglandin:}

A gel or pessary (like a small tampon) is inserted into your vagina. This slowly releases artificial prostaglandin over a number of hours causing your cervix to soften and open up (dilate). You will need to lie down for at least 30 minutes afterward to help it work on your cervix.

Artificial rupture of membranes (breaking your waters):

During a vaginal examination, a small opening is made in the membranes around your baby. This allows the fluid around your baby to drain out and can sometimes be enough to get your contractions going. Walking around afterward may help your contractions start. However, most women will also need an artificial oxytocin infusion to start their contractions ${ }^{(20)}$.

\section{Oxytocin:}

Natural oxytocin is a hormone that causes your uterus to contract. Artificial oxytocin in an intravenous (IV) drip is used to start or increase your contractions. It is usually only started after your waters have broken. Having your baby's heart rate monitored with a CTG machine during your labor is strongly recommended.

\section{Inducing labor using oxytocin}

This method of induction is done at the hospital. You will be connected to a monitor, which will record your baby's heartbeat and any contractions you are having. Your nurse will put an intravenous (IV) in your arm to give you a medication called oxytocin. Oxytocin is the hormone that is naturally made by the body to start labor. The amount of oxytocin is gradually increased, based on your body's and your baby's response. As the medication is increased labor contractions may begin. During induction, your nurse and doctor or midwife will closely observe you and your baby. Oxytocin does not always help start contractions. If this happens, your doctor or midwife may try another method to start labor ${ }^{(21)}$.

\section{Misoprostol}

Induction of labor continues to be a commonly performed obstetric procedure in the United States-in nearly $16 \%$ of pregnancies ${ }^{(22)}$. This procedure is often undertaken with prostaglandin compounds that are administered vaginally. These are usually prostaglandin E2 compounds, although misoprostol, a prostaglandin E1 analog, is being increasingly used for this purpose. Our own reports attest to the efficacy of this agent in comparison with various preparations of prostaglandin $\mathrm{E}^{(23)}$. Other researchers have reported the use of the medication in patients with a 
cervix that is more dilated and effaced than has been required in our ongoing trials ${ }^{(24)}$. Meta-analysis of vaginally administered misoprostol has not shown any increase in adverse neonatal outcome in comparison with other agents. Oral administration of misoprostol is appealing for several reasons, including convenience and lack of invasiveness. Fewer cervical examinations could also potentially result in lower peripartum infection rates. Oral administration, if proved safe and effective, could potentially reduce overall hospitalization time by permitting administration of the medication in an outpatient setting ${ }^{(25)}$.

There are risks involved with every medical procedure, including induction of labor. Although there are risks, it is important to realize that:

1. complications do not happen very often.

2. the members of the healthcare team have the knowledge, skills and equipment needed to safely perform these procedures and treat complications if they arise.

It is possible that the chosen method of induction is not successful in starting contractions and keeping labor going. If this happens, doctor or midwife will reassess the situation and decide if another method can be used or other plans need to be made for baby's birth. When labor is induced there is a greater chance that the doctor or midwife will need to assist baby's birth with forceps or a vacuum, or deliver the baby by cesarean section.

Although it is rare, oxytocin or PG gel can cause contractions to come too close together or last too long. When this happens, the baby's heart rate may drop. Usually the baby's heart rate returns to normal.

However, the oxytocin may need to be decreased or stopped. If the baby's heart rate does not return to normal, an emergency cesarean section would need to be done. Too many contractions may cause your uterus to tear. If this occurs, an emergency cesarean section would be necessary. When membranes rupture, there is a slight risk that the baby's umbilical cord could come through the cervix into the vagina. If this happens, the baby's heart rate may drop and the baby would need to be delivered very quickly, usually by cesarean section. If the Women had a cesarean birth before, your doctor or midwife will discuss the risks of induction with you.

It can be hard to predict how long baby will take to be born-just like it is hard to know when labor starts naturally. It might be shorter if the women have had a baby before, or hercervix is 'readier' at the beginning. Softening your cervix can take 12 hours or more. Sometimes more than one method is needed, making this part longer. contractions might start as your cervix softens and opens, but usually you will also need oxytocin. (after start contracting) can also take 12 hours or more. There may also be delays in starting a method of induction if the birthing unit is unexpectedly busy or there is an emergency.

Labor induction may be more painful for women, leading to increased use of analgesics and other medications to relieve pain ${ }^{(26)}$. These interventions have been reported to increase the risk of cesarean delivery ${ }^{(27)}$. However, studies in this issue show different results. One study showed that while overall cesarean delivery rates in 1990-1997 were at or below $20 \%$, elective induction was associated with a doubling of cesarean sections. Another study showed that spontaneous induction of preterm delivery increased the rate of cesarean delivery by two to three times (28). A recent study suggests that induction may increase the risk of the cesarean section is performed before the fortieth week of pregnancy, but has no effect or actually reduces risk if performed after the fortieth week ${ }^{(29)}$. The most recent literature on the effect of labor induction on cesarean section shows that cesarean delivery is not increased as a result of induction of labor, but may actually be reduced ${ }^{(30)}$. 


\section{Methods: -}

The study samples

The study sample consisted of (100) women who had delayed pregnancy, the fetus died in the abdomen and those who frequented Baghdad Hospital.

They were divided into two groups. The first group received oxytocin and the second group received misoprostol.and any contraindication to the use of misoprostol or oxytocin. The two groups were compared.

The researcher chose (20) women who died in their babies for any reason, and should undergo the abortion, and were divided into two groups to identify the effectiveness of each drug consisted of each group of (10) women, and the first group in each sample is that the drug received misoprostol, and the second group received the drug oxytocin.

After being interviewed, the women who met the eligibility criteria were invited to voluntarily participate in the study. Those who accepted were carefully informed of the aims and procedures of the study and then asked to sign the informed consent form. Following this, the heart rate was monitored to ensure wellbeing before the onset of induction.

Therandom allocation procedure was determined by opening a sequentially numbered envelope, thereby determining whether that woman should receive either misoprostol or oxytocin. This random sequence was generated by computer and the investigator was unaware of the sequence.

\section{Study Procedures:}

For women receiving misoprostol, $25 \mu \mathrm{g}$ were administered in the posterior fornix of the vagina. The dose was repeated every 4 hours, until a pattern of at least 3 contractions every 10 minutes was obtained. The maximum dose was $200 \mu \mathrm{g}$. If this contraction pattern had not been reached by four hours after the administration of the eighth dose, induction was considered to have failed. After the ideal pattern of contractions was reached, misoprostol was no longer administered.

For the women in the oxytocin group, an intravenous infusion of $2 \mathrm{mU} / \mathrm{min}$ was used, which was doubled at 30minute intervals until the appropriate contraction pattern was obtained. The infusion dose was increased to a maximum of $20 \mathrm{mU} / \mathrm{min}$, at which point it was then maintained constant. If the contraction pattern had not been induced by the time that $15 \mathrm{IU}$ of oxytocin had been infused, the induction was also considered to have failed. Even after the ideal pattern was reached, oxytocin flow was continued.

Induction is successful when three uterine contractions occur within 10 minutes, with changes in the cervix, or miscarriage within 24 hours of induction.

Incitement can be said to have failed when labor does not occur after six doses of induction have been terminated or 24 hours after initiation of induction on a regular basis.

Results were observed, studied in detail, and results were extracted using the medical census.

\section{Result: -}

There were no significant differences between the first group and the second group with regard to the average age of women and their average pregnancy. The mean age was determined and the results were as follows:

Label 1: - Description of the sample

\begin{tabular}{|l|l|l|}
\hline & Grope 1 & Grope 2 \\
\hline middle age & 22,4 & 24,3 \\
\hline Average age at conception & 25,5 & 25,3 \\
\hline Number of grooves & 32 & 41 \\
\hline Cervical widening & $190(95 \%)$ & $187(93 \%)$ \\
\hline
\end{tabular}

The comparison was then performed according to the success or failure of the induction, vaginal delivery, hyperactivity, and the incidence of contractions, duration of induction and even vaginal delivery 
The duration of induction and even the effective length of labor and the results were as follows:

Label 2: - Comparison between the two drugs in the case of late menstruation

\begin{tabular}{|l|l|l|l|}
\hline & Grope 1 & Grope 2 & Value P \\
\hline Success induction & 41 Women & 30 Women & 0,000 \\
\hline failure induction & 9 Women & 20 Women & 0,000 \\
\hline vaginal delivery & 40 Women & 25 Women & 0,000 \\
\hline hyperactivity & 1 Women & 12 Women & 0,000 \\
\hline incidence of contractions & 1 Women & 15 Women & 0,000 \\
\hline $\begin{array}{l}\text { duration of induction and even } \\
\text { vaginal delivery }\end{array}$ & 527 Minutes & 968 Minutes & 0,000 \\
\hline $\begin{array}{l}\text { The duration of induction and } \\
\text { even the effective length of labor }\end{array}$ & 501 Minutes & 954 Minutes & 0,000 \\
\hline
\end{tabular}

For the first group, misoprostol showed that there were (41) successful cases of agitation compared to (30) cases of success in the second drug. Therefore, after analyzing the results, the first drug is found to be more effective in the number of cases of success of induction.

As for the number of failures, misoprostol showed that the cases of agitation failure amounted to (9) cases compared to oxytocin, the number of cases of failure (20) case and therefore misoprostol is the most effective in cases of less failure to induce.

A smaller number of cases were detected with regard to excessive alertness and contractions. The misoprostol score was faster in the induction of oxytocin, and therefore misoprostol was most effective in induction of labor.

This study showed that a $25-\mu \mathrm{g}$ dose of misoprostol at four-hourly intervals might be a more effective agent than oxytocin for cervix ripening and labor induction, for the term and post-term pregnant women with unripe services.

The present study showed that the average time interval to the onset of labor and also to the occurrence of vaginal delivery was significantly shorter in the misoprostol group. These same results have also been found by many other authors. Campos et al. studied ${ }^{(31)}$, misoprostol $(50 \mu \mathrm{g}$, single dose, vaginally) and oxytocin (2 to $32 \mathrm{mU} / \mathrm{min})$ and found an average of $552 \mathrm{~min}$ to the beginning of labor for the misoprostol group, versus $745 \mathrm{~min}$ for the oxytocin group, presenting statistical significance. These findings are consistent with our results.

An American study ${ }^{(32)}$, demonstrated that the average time interval until the occurrence of vaginal delivery was also shorter for misoprostol (50 $\mu \mathrm{g}$ at four-hourly intervals) than for oxytocin (11 hours versus 18), presenting statistical significance. In Turkey, another study showed the same result, presenting quite similar averages when compared to this study (9 hours versus 15$){ }^{(33)}$. The average differences in these intervals are related to the dose, route and administration interval. There are also some studies on pregnant women with favorable cervices for induction or previous administration of dinoprostone before the start of induction.

This study shows favorable results regarding the use of misoprostol as a modifying agent of the cervix and for inducing labor. Investigations need to be continued, in order to find the smallest useful dose that facilitates cervix ripening and labor induction without causing any uterine contractility alteration or harm to the fetus.

The researcher studied the effectiveness of the drug as well as in women during early pregnancy, the women who died in their babies before their arrival in the birth and full growth, where she took the 20 women who died their fetus and divided them into two groups: the first group consisted of (10) Women received misoprostol, and the second group (10) women received oxytocin. The results were as follows: 
Label 3: - Comparison of real estate in cases of premature birth

\begin{tabular}{|l|l|l|l|}
\hline & Grope 1 & Grope 2 & Value P \\
\hline Success induction & 8 Women & 5 Women & 0,000 \\
\hline failure induction & 1 Women & 5 Women & 0,000 \\
\hline vaginal delivery & 8 Women & 5 Women & 0,000 \\
\hline hyperactivity & 1 Women & 8 Women & 0,000 \\
\hline incidence of contractions & 5 Women & 7 Women & 0,000 \\
\hline $\begin{array}{l}\text { duration of induction and even } \\
\text { vaginal delivery }\end{array}$ & 500 Minutes & 540 Minutes & 0,000 \\
\hline $\begin{array}{l}\text { The duration of induction and } \\
\text { even the effective length of labor }\end{array}$ & 432Minutes & 600 Minutes & 0,000 \\
\hline
\end{tabular}

The results showed that the misoprostol drug received by the first group was more effective than the drug received by the second group in cases of induction of premature birth due to fetal death.

\section{Conclusions: -}

The use of misoprostol sublingual should be encouraged at a dose of $50 \mathrm{mg}$ every 4 hours for induction of labor in the case of complete pregnancy and, in case of fetal death, under certain conditions. Especially when the Bishop index is low, and Misoprostol is relatively cheap and is available and easy to maintain and use and more receptive to the lady of venous oxytocin and the complications of sublingual misoprostol are acceptable and manageable.

\section{References: -}

1. Joseph, Mercy, Labor Induction, Labor and Delivery 5301 McAuley Drive, Ypsilanti, MI 48197,2014, p1

2. Sanchez-Ramos L, Kaunitz AM, Del Valle GO, Delke I, Schroeder PA, Briones DK. Labor induction with the prostaglandin E1 methyl analogue misoprostol versus oxytocin: a randomized trial. Obstet Gynecol 1993; 81:332-6.

3. Xenakis EM, Piper JM, Conway DL, Langer O. Induction of labor in the nineties: conquering the unfavorable cervix. Obstet Gynecol 1997; 90:235-9.

4. ACOG Committee Openion. Induction of labor With Misoprostol No.228 Washington, DC: ACOG ;1999. Obstet Gynecol 2003; 94; 1-2.

5. Deborah Wing, MD, Induction of labor; indications, techniques, and complications; form UpToDate. June 2005.

6. Eray caliskan, Harika Bodur, Misoprostol 50 ug Sublingually versus Vaginally for Labor Induction at Term: A Randomized Study, Gynecologic and Obstetric Investigation 2005; 59 :155-161.

7. Fletcher H, Mitchell S, Frederick J, Simeon D, Brown D. IntravaginaI misoprostol versos dinoprostone as cervical ripening and laborinducing agents. Obstet Gynecol 1994; 83:244-7

8. Chuck FJ, Huffaker BJ. Labor induction with intravaginal misoprostol versus intracervicaI prostaglandin E 2 gel (Prepidil gel): Randomized comparison. Am J Obstet GynecoI 1995; 173:1137-42.

9. Owen J, Hauth JC. Oxytocin for the induction or augmentation of labor. Clin Obstet Gynecol 1992; 35:464-75,

10. Hofmeyer GJ, Gulmezoglu AM. Vaginal misoprostol for cervical ripening and labor induction in late pregnancy (Cochrane Review). In: The Cochrane Library, Issue 2, 2000. Oxford: Update Software.

11. Clark A, Cook V, Hill P, Spinnato J. Cervical ripening and labor induction: misoprostol vs. dinoprostone. Am J Obstet Gynecol 1998; 178:30.

12. Bennett KA, Butt K, Crane JMG, Hutchens D, Young DC. A masked randomized comparison of oral and vaginal administration of misoprostol for labor induction. Obstet Gynecol 1998; 92:481-6.

13. Kubli FW, Hon EH, Khazin AF, Takemura H. Observations on heart rate and $\mathrm{pH}$ in human fetus during labor. Am J Obstet Gynecol 1969; 104:1190-206

14. Toppozada MK, Anwar MYM, Hassan HA, El-Gazaerly WE. Oral or vaginal misoprostol for induction of labor. Int J Gynaecol Obstet 1997; 56:135-9.

15. Wing DA, Ham D, Paul RH. A comparison of orally administered misoprostol with vaginally administered misoprostol for cervical ripening and labor induction. Am J Obstet Gynecol 1999;180(5):1155-60

16. Toppozada MK, Anwar MYM, Hassan HA, El-Gazaerly WE. Oral or vaginal misoprostol for induction of labor. Int J Gynaecol Obstet 1997; 56:135-9. 
17. Xenakis EM, Piper JM, Conway DL, Langer O. Induction of labor in the nineties: conquering the unfavorable cervix. Obstet Gynecol 1997; 90:235-9 .

18. Buser D, Mora G, Arias F. A randomized comparison between misoprostol and dinoprostone for cervical ripening and labor induction in patients with unfavorable cervices. Obstet Gynecol 1997;89(4):581-5.

19. Wing DA, Ham D, Paul RH. A comparison of orally administered misoprostol with vaginally administered misoprostol for cervical ripening and labor induction. Am J Obstet Gynecol 1999;180(5):1155-60

20. Kadanali S, Küçüközkan T, Zor N, Kumtepe Y. Comparison of labor induction with misoprostol vs. oxytocin/prostaglandin E2 in term pregnancy. Int J Gynaecol Obstet 1996;55(2):99-104.

21. Buser D, Mora G, Arias F. A randomized comparison between misoprostol and dinoprostone for cervical ripening and labor induction in patients with unfavorable cervices. Obstet Gynecol 1997;89(4):581-5.

22. Ventura SJ, Martin JA, Curtin SC, Mathews TJ. Report of final natality statistics, 1995. Monthly vital statistics report; vol. 45, No. 11 (Suppl). Hyattsville (MD): National Center for Health Statistics; 1997.

23. Wing DA, Jones MM, Rahall A, Goodwin TM, Paul RH. Misoprostol: an effective agent for cervical ripening and labor induction. Am J Obstet Gynecol 1995; 172:1811-6.

24. Sanchez-Ramos L, Kaunitz AM, Del Valle GO, Delke I, Schroeder PA, Briones DK. Labor induction with the prostaglandin E1 methyl analogue misoprostol versus oxytocin: a randomized trial. Obstet Gynecol 1993; 81:332-6.

25. Ngai SW, To WK, Lao T, Ho PC. Cervical priming with oral misoprostol in pre-labor rupture of membranes at term. Obstet Gynecol 1996; 87:923-6.

26. Patel A, Gilles JM, Moffett D, Mahram R, Diro M, Burkett G. Can misoprostol be interchanged with oxytocin for augmentation of labor? Obstet Gynecol 2000;95(Suppl):105.

27. Kadanali S, Küçüközkan T, Zor N, Kumtepe Y. Comparison of labor induction with misoprostol vs. oxytocin/prostaglandin E2 in term pregnancy. Int J Gynaecol Obstet 1996;55(2):99-104.

28. Patel A, Gilles JM, Moffett D, Mahram R, Diro M, Burkett G. Can misoprostol be interchanged with oxytocin for augmentation of labor? Obstet Gynecol 2000;95(Suppl):105.

29. Kramer RL, Gilson GJ, Morrison DS, Martin D, Gonzales JL, Qualls CR. A randomized trial of misoprostol and oxytocin for induction of labor: safety and efficacy. Obstet Gynecol 1997;89(3):387-91.

30. Hofmeyer GJ, Gulmezoglu AM. Vaginal misoprostol for cervical ripening and labour induction in late pregnancy (Cochrane Review). In: The Cochrane Library, Issue 2, 2000. Oxford: Update Software.

31. Campos GA, Guzmán S, Rodriguez JG, Voto LS, Margulies M. Misoprostol - un análogo de la PGE1 - para la inducción de parto a término: estudio comparativo y randomizado con oxitocina. Rev Chil Obstet Ginecol 1994;59(3):190-5. discussion 195-6.

32. Ramos L, Kaunitz AM, Del Valle GO, Delke I, Schroeder PA, Briones DK. Labor induction with the prostaglandin E1 methyl analogue misoprostol versus oxytocin: a randomized trial. Obstet Gynecol 1993;81(3):332-6.

33. Kadanali S, Küçüközkan T, Zor N, Kumtepe Y. Comparison of labor induction with misoprostol vs. oxytocin/prostaglandin E2 in term pregnancy. Int J Gynaecol Obstet 1996;55(2):99-104. 